\title{
Em busca da inovação: os especiais multimídia para comunicar a ciência em uma instituição da Amazônia
}

In search of innovation: the special multimedia to communicate science in an institution in the Amazon

En busca de la innovación: los especiales multimedia para comunicar la ciencia en una institución de la Amazonía

Tarcízio MACEDO, Brasil

Universidade Federal do Rio Grande do Sul (UFRGS)

tarcizio.macedo@bol.com.br

tarcizio.macedo@ufrgs.br

Elaide MARTINS, Brasil

Universidade Federal do Pará

elaidemartins@gmail.com

Chasqui. Revista Latinoamericana de Comunicación

N. ${ }^{\circ} 144$, Agosto - Noviembre 2020 (Sección Diálogo de saberes, pp. 279-298)

ISSN 1390-1079 / e-ISSN 1390-924X

Ecuador: CIESPAL

Recibido: 01-04-2020/Aprobado: 04-07-202O 


\section{Resumo}

Este estudo empreende uma reflexão sobre a inovação no jornalismo científico, com enfoque nos conteúdos e narrativas produzidos pelo Laboratório de Comunicação Multimídia (LabCom) do Museu Paraense Emílio Goeldi, a mais antiga instituição de pesquisa na Amazônia brasileira. Busca-se explorar o modo como essa secular instituição atua em possíveis tendências inovadoras no jornalismo em tempos de convergência. Sob esta perspectiva, o artigo investiga, especificamente, os especiais multimídia produzidos pelo LabCom do museu, voltados à inovação na comunicação científica a fim de visibilizar suas ações e valorizar a cidadania e a democratização do conhecimento na Amazônia.

Palavras-chave: Inovação no jornalismo científico, especiais multimídia,inovação, Laboratório de Comunicação Multimídia (LabCom), Museu Paraense Emílio Goeldi (MPEG, Amazônia

\section{Abstract}

This study undertakes a reflection on innovation in scientific journalism, focusing on the contents and narratives produced by the Laboratory of Multimedia Communication (LabCom) of the Museu Paraense Emílio Goeldi, the oldest research institution in the Brazilian Amazon. It seeks to explore how this secular institution acts on possible innovative trends in journalism in times of convergence. From this perspective, the article specifically investigates the multimedia specials produced by the museum's LabCom, focused on innovation in scientific communication in order to visualize its actions and value citizenship and the democratization of knowledge in the Amazon.

Keywords: Innovation in scientific journalism, specials multimedia, innovation,Multimedia Communication Laboratory (LabCom), Museu Paraense Emílio Goeldi (MPEG), Amazon

\section{Resumen}

Este estudio emprende una reflexión sobre la innovación en el periodismo científico, con enfoque en los contenidos y narrativas producidos por el Laboratório de Comunicação Multimídia (LabCom) del Museu Paraense Emilio Goeldi, la institución de investigación más antigua de la Amazonia brasileña. Se busca explorar el modo en que esta secular institución actúa en posibles tendencias innovadoras en el periodismo en tiempos de convergencia. En esta perspectiva, el artículo investiga, específicamente, los especiales multimedia producidos por el LabCom del Museo, volcados a la innovación en la comunicación científica a fin de visibilizar sus acciones y valorar la ciudadanía y la democratización del conocimiento en la Amazonia.

Palabras clave: innovación en el periodismo científico, especiales multimedia, innovación, Laboratorio de Comunicación Multimedia (LabCom), Museo Paraense Emilio Goeldi (MPEG), Amazonia 


\section{Introdução}

Dada a conjuntura na qual se encontra o jornalismo contemporâneo constantemente confrontado a acompanhar as atualizações inseridas pelos avanços tecnológicos - e a pouca produção de estudos específicos que procurem entender as dinâmicas e singularidades da comunicação da ciência em uma região como a Amazônia, mais especificamente no âmbito das ações desenvolvidas no jornalismo científico, a análise dos aspectos da inovação no jornalismo empregados por instituições de pesquisa, ensino e extensão é tão necessária quanto urgente.

É reconhecido que na sociedade em rede a mídia adquire um papel essencial no processo de democratização da ciência, conforme nos lembra Graça Caldas (2011). No entanto, é uma tarefa complexa pensar em estratégias para fomentar o interesse em temas relacionados à ciência, a fim de inseri-la no cotidianos das pessoas, sobretudo em função de alguns obstáculos, como a falta de disponibilidade de alguns produtores de conhecimento em evidenciarem suas descobertas, de interesse da mídia em publicizá-las (Beltrão, 2010a) e mesmo do público em consumi-las, dada a multiplicidade de ofertas de conteúdos atualmente.

Diante desse cenário, a inovação jornalística desponta como uma oportunidade para utilizar linguagens e formatos com mais apelo perante os múltiplos públicos existentes. No jornalismo, a inovação pode ser entendida a partir de vários aspectos, seja em suas narrativas, recursos tecnológicos e interativos, processos produtivos ou etapas de consumo e circulação de conteúdos.

Neste trabalho, pretendemos refletir sobre a inovação no jornalismo científico com enfoque especial para os conteúdos e narrativas do Laboratório de Comunicação Multimídia (LabCom), vinculado ao Serviço de Comunicação Social (SCS) do Museu Paraense Emílio Goeldi (MPEG), a mais antiga instituição de pesquisa da Amazônia e o segundo maior e mais antigo museu de história natural do Brasil, fundado em 1866 em Belém, capital do estado do Pará, e hoje vinculado ao Ministério da Ciência, Tecnologia, Inovações e Comunicações do Brasil. Nosso olhar, portanto, direciona-se às ações do LabCom do MPEG, que tem atuado na concepção e implementação de estratégias para fomentar o interesse pela ciência.

Como método de pesquisa, adotamos o Estudo de Caso, estratégia que possui grande "capacidade de lidar com uma ampla variedade de evidências - documentos, artefatos, entrevistas e observações” (Yin, 2001, p. 27). Assim, realizamos a observação direta de um conjunto de elementos dispostos em dez reportagens, formatos, tecnologias e outros produtos, além de uma entrevista semiestruturada presencial com a chefe do SCS, a jornalista Joice Santos. O objetivo desta entrevista foi obter insumos para complementar os dados 
obtidos pela observação direta, a partir da compreensão das etapas, processos produtivos, percepções, contextos e usos da inovação pelo LabCom do MPEG.

A observação qualitativa implica muito mais do que uma mera contemplação, de acordo com Roberto Sampieri, Carlos Collado e Pilar Lucio (2014), reivindica ao investigador entrar profundamente em situações sociais e manter, por vezes, um papel ativo, assim como uma reflexão contínua - estando, ainda, atento aos detalhes, eventos, sucessos e interações. A técnica de observação direta, assim, procura explorar e descrever ambientes, comunidades, culturas e os aspectos da vida social, analisando seus significados e sujeitos.

Por sua vez, Valdete Boni e Silvia Quaresma (2005) argumentam que a entrevista semiestruturada combina perguntas abertas e fechadas, nas quais o interlocutor pode discorrer sobre um conjunto de questões previamente estabelecidas sobre um tema proposto pelo pesquisador. Muito próximo de um contexto informal, o uso dessa técnica permite que o pesquisador adicione perguntas para aprofundar questões levantadas pelo entrevistado.

Como recorte empírico, elegemos duas séries especiais multimídia publicadas entre 2015 e 2017 no portal do Museu Emílio Goeldi. As séries, produzidas pelo LabCom, são compostas por dez reportagens, vídeos, imagens, gifs (sequências e imagens em movimento), ilustrações, design e vídeos com tutoriais para montagem dos brindes, no caso os paper toys, miniaturas de animais em papel. A coleta de dados e a análise foram realizadas de novembro de 2018 a janeiro de 2019.

Como referencial teórico, utilizamos uma das categorias que compõe a tipologia adotada por Ana Flores (2017) para compreender o jornalismo de inovação, a saber: conteúdo e narrativa ${ }^{2}$. Aproximamos, ainda, esta categoria com o debate acerca da inovação no jornalismo (Martins, 2018; Martins; Castro \& Vinagre, 2018; 2018; Longhi \& Flores, 2017; Giacomini Filho, 2015; Rossetti, 2013) e dos conceitos de especial multimídia (Longhi, 2010, 2014) e de multimidialidade (Salaverría, 2005, 2014) para enfocar a produção multimídia do LabCom, a seguir.

\section{0 projeto Viva Amazônia e as séries especiais multimídia do LabCom/MPEG}

Criado em setembro de 2009, a partir de um projeto de popularização da ciência financiado pelo Conselho Nacional de Desenvolvimento Científico e Tecnológico (CNPq), o Laboratório de Comunicação Multimídia é uma das unidades que integram o SCS-MPEG. Entre suas incumbências, está gerenciar os perfis nos sites de redes sociais, produzir especiais - como as séries multimídia - e experimentar formatos, ferramentas, tecnologias e narrativas.

Disponivel em: https://www.museu-goeldi.br/.

As demais categorias são: tecnologia e formato; e modelo de negócio, contudo, escapam o escopo de discussão deste trabalho. 
Entre as ações do LabCom, estão as séries de reportagens multimídia, formato idealizado como parte do projeto Viva Amazônia, voltado para compartilhar informações acerca do bioma amazônico e das coleções que compõem os acervos científicos do museu. O LabCom foi pioneiro ao implementar esse projeto como uma estratégia para divulgar os acervos institucionais do MPEG, agregando comunicação, jornalismo, educação, sites de redes sociais, multimídia, além de pesquisa de campo e informações técnicas acerca do manejo zoobotânico (Fernandes, 2017).

A série multimídia "Aves e Mamíferos" foi lançada em agosto de $2015^{3}$, durante as comemorações de aniversário dos 149 anos do Museu Goeldi e 120 anos do Parque Zoobotânico. O público foi convidado a selecionar quatro animais que seriam tema da série, veiculada até setembro de 2015, para compor os paper toys, brinquedos de papel impressos e montados (Figura 1).

Figura 1 - Paper toy com a miniatura de papel da onça-pintada, disponibilizada na reportagem sobre o animal.

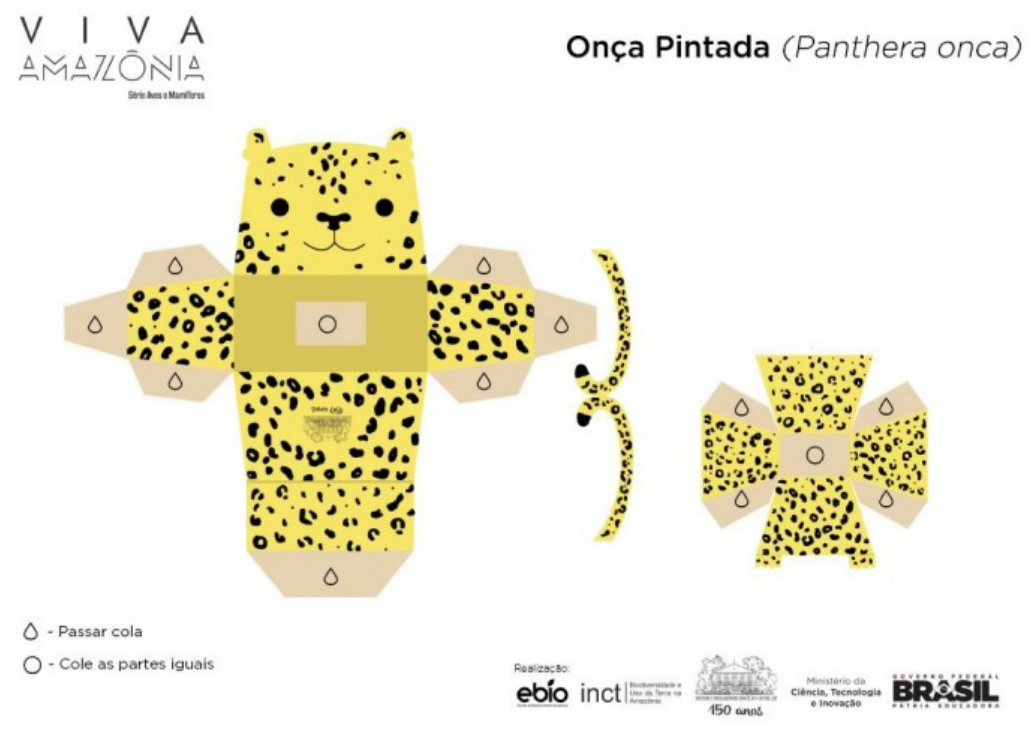

Fonte: Portal do Museu Goeldi, 2015

3 Com um total de quatro reportagens especiais, lançadas semanalmente, disponíveis nos links a seguir, em ordem cronológica de publicação: Araracanga (https://bit.ly/2XyWtuh), Ariranha (https://bit.ly/2LdAcAt), Guará (https://bit.ly/2LlikNH) e Onça-pintada (https://bit.ly/2xCMnOT). 
Já a série “As Anciãs do Museu Goeldi”, lançada em julho de $2016^{4}$, destacou curiosidades sobre a coleção botânica do MPEG. Com foco nas árvores históricas e mais antigas do parque, seis espécies foram divulgadas a partir de reportagens, vídeo-reportagens e fotografias do acervo do museu, além de gifs e papeis de parede (Figura 2) para computadores, smartphones e tablets. A maioria desse conteúdo estava disponível no site "Revitalização do Parque do Museu Goeldi”, mas, em decorrência de uma decisão do Serviço de Tecnologia da Informação (SETIC) do MPEG, o site foi retirado do ar e grande parte do seu conteúdo está inacessível.

Figura 2 - Divulgação dos papeis de parede nas reportagens do portal do MPEG.

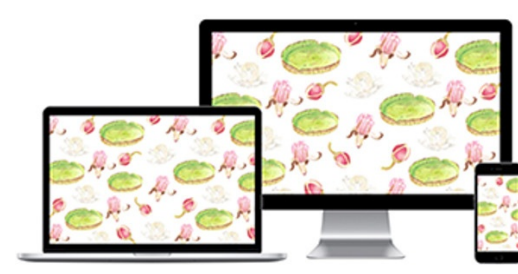

Baixe seu wallpaper para smartphone, notebook e desktop (llustração: Livia Prestes)

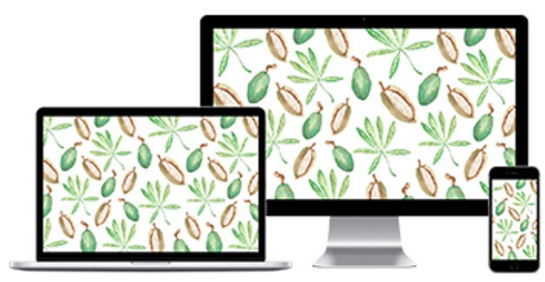

Baixe o wallpaper da Samaumeira para o celular ou computador (llustração: Livia Prestes)

Fonte: Portal do Museu Goeldi, 2016.

$\mathrm{Na}$ aba do projeto Viva Amazônia ${ }^{5}$, apenas os links para os vídeos tutorias de montagem dos paper toys e as vídeo-reportagens sobre os animais ainda estão acessíveis. Assim, a localização das dez reportagens somente foi possível a partir do uso da ferramenta de busca do portal, utilizando como palavraschave os nomes dos animais selecionados e as expressões "Viva Amazônia", "Aves e Mamíferos" e "As Anciãs do Museu Goeldi”. A partir da análise dessas duas séries, buscamos compreender o modo como uma secular instituição atua diante de uma possível tendência à inovação no jornalismo contemporâneo. A seguir, desenvolvemos uma breve problematização sobre a inovação nos conteúdos e narrativas jornalísticos.

4 Com um total de seis reportagens especiais, lançadas mensalmente até novembro de 2016. A sexta reportagem especial só foi publicada em agosto de 2017 em decorrência, sobretudo, da reestruturação do LabCom no SCS do MPEG, diante da falta de verba e do risco da instituição de fechar algumas unidades, causando grande repercussão local e nacional. As seis reportagens estão disponíveis nos links a seguir, em ordem cronológica de publicação: Vitóra-régia (https://bit.ly/2/trRIZ), Seringueira (https://bit. ly/36pvYOI), Samaumeira (https://bit.ly/2JTKZjP), Guajará (https://bit.ly/3pdQZEi), Castanheira (https:// bit.ly/3pkm21h) e Palmeiras (https://bit.ly/36qBXma)

5 Disponivel em: https://bit.ly/2NLz4Gn. 


\section{Jornalismo e inovação nos conteúdos e narrativas: alguns aspectos e concepções}

A diversidade de públicos, tecnologias e comportamentos tencionam constantemente os formatos tradicionais do jornalismo em uma dinâmica que incita a inovação em variados aspectos da atividade (Flores, 2017). Atualmente, é comum pensar a prática jornalística para além de seus modelos clássicos. Elaide Martins (2018) e Martins et al. (2018) argumentam que as manifestações das inovações jornalísticas se apresentam de múltiplas formas e revelam-se tanto em produtos ou serviços, quanto por meio dos processos, equipe e gestão.

Observada no jornalismo, em concordância com Longhi e Flores (2017), a inovação não somente decorre das tecnologias implantadas ou nos produtos finais, mas igualmente a partir de uma dinâmica de reestruturação das redações, com a criação de departamentos dedicados à inovação ou, ainda, na formação de seus próprios centros de inovação - laboratórios internos, como o LabCom do MPEG - e parcerias externas para a criação de produtos inovativos. "Nos casos mais significativos, tudo isso resulta em produtos e conteúdos revolucionários" (Longhi \& Flores, 2017, p. 26).

Frequente em qualquer levantamento acerca da evolução das estratégias narrativas no jornalismo on-line nos últimos anos, inovação é uma concepção que, em geral, aparece associada, no jornalismo, ao uso de formas expressivas de modo mais inovativo, abrangendo imagem, texto, vídeo, áudio e infografia (Longhi \& Flores, 2017). Segundo Martins (2018), os processos produtivos, as formas narrativas, os dispositivos tecnológicos e/ou interativos e as etapas que compõem a dinâmica de circulação e consumo das informações são aspectos que auxiliam na compreensão da inovação no jornalismo.

Ao se relacionar aos conteúdos, a inovação no jornalismo pode despontar tanto em editorias como em séries especiais ou produtos noticiosos pontuais, laboratórios midiáticos próprios ou a partir de parcerias entre jornais e outras empresas de tecnologia e mídia (Longhi \& Flores, 2017). No ambiente das plataformas digitais, os elementos multimidiáticos combinam-se tanto de forma aglutinada, quanto lado a lado (Flores, 2017; Salaverría, 2005). A propagação de novas linguagens e o processo de associação delas por integração foram apresentando novos modos de se conceber o próprio jornalismo. Para Flores (2017), tais transformações também propiciaram elementos de inovação focalizados em produtos jornalísticos que trouxeram, para além da tecnologia, conteúdos e narrativas inéditas.

As Grandes Reportagens Multimídia (GRM) são um exemplo e sugerem, para muito além da tecnologia, as diferentes frentes que a prática jornalística pode encaminhar. A forma pela qual o texto é organizado possibilita inovações no próprio processo de apuração, no potencial criativo do editor e do repórter e na atenção à fonte e ao relato. Contudo, reafirmamos a relevância do trabalho jornalístico de qualidade para qualquer instância da atividade e destacamos a 
necessidade de recursos financeiros para inovar no jornalismo (Flores, 2017; Martins, 2018).

Portanto, seguir essa tendência requer investimentos que, tratando-se de uma instituição púbica de pesquisa, estão minguando cada vez mais no cenário brasileiro. Essa situação agravou-se nos últimos anos pela agenda política de constantes desmontes e contingenciamento de verbas no quadro da CT\&I no Brasil. Quando questionada sobre um projeto submetido a um edital do CNPq em 2017, cujo parecer de rejeição ${ }^{6}$ explicitou as dificuldades e os desafios de promover a inovação na comunicação de uma instituição pública no Brasil, a chefe do SCS tratou de reposicionar nossa pergunta para um quadro mais amplo.

É uma dificuldade inovar num quadro em que não tem recurso para a comunicação da ciência. E não é da instituição, a instituição tem o mínimo necessário para se manter aberta. O que nós temos hoje possibilita ao museu não parar, mas ele não tem recursos para apostar em pesquisa. Então, isso a gente capta lá fora. O recurso do PCI [Programa de Capacitação Institucional] permite que a gente traga profissionais para cá, para desenvolver estudos ou desenvolver uma ferramenta interessante para gente - e fazer estudos nessa área de inovação. E qual é a nossa dificuldade? A forma que foi visto esse [projeto], pela burocracia do ministério. (Joice Santos. Entrevista pessoal. Janeiro de 20197)

A fala dajornalista evidencia uma forte crise que afeta o trabalho desenvolvido pelos setores de comunicação dessas instituições, bem como a escassez de verbas para o fomento da popularização da ciência. Em 2009, conforme a jornalista e ex-chefe do SCS do MPEG, Jimena Beltrão (2010b), o setor chegou a contar com 12 pessoas, entre profissionais e estudantes de comunicação que compunham a Agência Museu Goeldi. Atualmente, o quadro foi reduzido pela metade, afetando diretamente a produção de conteúdos especiais. Essa situação impacta, diretamente, no investimento em inovação na comunicação da ciência produzida no MPEG.

Esse contexto, portanto, deve ser evidenciado na medida em que os impactos da crise orçamentária e da falta de investimento público nas ações do SCS do museu desdobram-se em significativos entraves em várias frentes de atuação do LabCom. Na seção seguinte, faremos uma breve revisão sobre o formato noticioso conhecido como "especial multimídia", a fim de fornecer insumos para a análise que se seguirá.

\section{3. $O$ que é o especial multimídia?}

Antes que adentremos no debate sobre o "especial multimídia" é preciso atentar à definição de dois conceitos necessários ao seu desenvolvimento:

6 Apresentou a 'justificativa' de que não havia necessidade de investir na pesquisa em Comunicação.

7 Entrevista realizada presencialmente pelo pesquisador Tarcízio Macedo, nas dependências do SCS do MPEG, em 09 de janeiro de 2019, em Belém-PA, Brasil. 
a multimidialidade e a interatividade. Em sua revisão acerca do conceito de multimidialidade no jornalismo, Ramón Salaverría (2014) identifica três acepções principais, a saber: como multiplataforma, como polivalência e como combinação de linguagens. A primeira se refere a uma "coordenação logística de distintos meios de comunicação" (Salaverría, 2014, p. 27), os quais dispõem de estratégias específicas para obter um melhor resultado coletivo. A segunda se associa a um processo caracterizado pela acumulação de distintas funções desempenhadas por um único jornalista. A terceira acepção, por fim, bastante presente no âmbito jornalístico, diz respeito a uma interpretação da multimídia como a combinação conjunta e simultânea de linguagens ou de formatos - texto, imagem, som, vídeo etc. Para Salaverría (2014), esta última é a acepção mais usual de multimídia.

Por sua vez, Alejandro Rost (2014) empreende uma análise acurada sobre os significados e sentidos das definições da interatividade, explorando estudos e tendências acerca do conceito. Rost (2014) considera a interatividade como a gradual capacidade (graus de interatividade) que um dado meio de comunicação possui para oferecer maior poder aos utilizadores, seja na seleção de conteúdos (o que o autor denomina de "interatividade seletiva"), seja nas possibilidades de expressão e comunicação (nomeada de "interatividade comunicativa") ${ }^{8}$.

Em suas pesquisas sobre formatos nos meios jornalísticos digitais, Raquel Longhi (2010) busca compreender e conceituar o que se define como "especiais multimídia", termo usado pelo próprio LabCom para definir seus projetos especiais. Para ela, o uso de recursos da hipermídia, a exemplo da multimidialidade, da interatividade e de elementos multimídia, por uma gama extensiva de formatos distintos torna o especial multimídia um tipo de produto jornalístico on-line que necessita de uma definição mais precisa e apurada. Afinal, como se pode definir o especial multimídia, uma vez que é usado como formato noticioso? De acordo com Longhi, a nomenclatura tem sido empregada para referir-se a uma determinada "web-reportagem, que se utiliza de elementos multimidiáticos integrados (imagens, sons e texto verbal), sendo também chamada de reportagem multimídia, narrativas multimídia, dentre outros" (2010, p. 150).

Segundo a pesquisadora, o uso dos termos "especiais" e "multimídia" aplica-se a formatos distintos que possuem, em comum, uma mesma particularidade: a existência de elementos multimídia, incorporados ou não, tais como som, imagens (estáticas ou em movimento) e texto. Salaverría (2005) aponta para uma simplicidade no uso da multimidialidade nos cibermeios atuais. Grande parte dos cibermeios que se apresentam como "multimídia" costuma usar somente imagens, textos e sons que são passíveis de ser consumidos de modo contínuo ou separados.

8 Para mais detalhes acerca do conceito de interatividade e dos diferentes níveis que possui, atentar para o trabalho de Rost (2014). 
Para o autor, apenas alguns cibermeios, mais especificamente aqueles de vanguarda e referência, iniciaram uma experimentação combinada dos elementos multimídia para formatar um discurso unificado. Salaverría (2005) argumenta que os cibermeios usam a multimídia com base em dois aspectos específicos: o primeiro por justaposição, isto é, quando os elementos (imagens, textos e sons) são colocados de modo desagregado e lado a lado; e o segundo por integração, quando o conjunto desses elementos são reunidos em um mesmo suporte e passam a criar uma unidade comunicativa para articular um discurso coerente e único.

Longhi propõe, pois, uma definição dos especiais multimídia como "grande reportagem constituída por formatos de linguagem multimídia convergentes, integrando gêneros como a entrevista, o documentário, a infografia, a opinião, a crítica, a pesquisa, dentre outros, num único pacote de informação, interativo e multilinear" (2010, p. 153). Nessa definição, que entende os especiais multimídia como um gênero do jornalismo on-line que possibilita outros gêneros jornalísticos, os formatos de linguagem multimídia convergentes são compostos por linguagem textual, sonora e/ou visual. São, assim, convergentes em decorrência das suas disposições estarem integradas (Longhi, 2010).

Os conteúdos multimídia vêm marcando a linguagem webjornalística, sejam eles explorados à exaustão ou não. Até o momento, o que era uma tímida utilização da multimídia, identificada por Salaverría (2005), vem se tornando um tipo de produto no qual ocorre a exploração mais apropriada das características multimídia dos meios digitais. Esse cenário previu um desenvolvimento dos formatos da notícia mais particulares do meio, que passaram a ganhar um lugar de destaque nos meios on-line.

As GRM são um ponto de virada nesse tipo de formato noticioso nojornalismo on-line (Longhi, 2014). Tratam-se, portanto, de um exemplo do contínuo processo de evolução dos usos potenciais da multimídia no contexto jornalístico. A autora empreende um processo de sistematização, baseado em graus de evolução, dos formatos expressivos multimidiáticos da notícia no jornalismo digital ${ }^{9}$, que identifica quatro fases distintas acerca dessa trajetória ${ }^{10}$, a saber: fase zero, entre 1995 a 1998; fase um, com os primeiros produtos multimídia (slide-shows noticiosos) no início dos anos 2000; fase dois, com os especiais multimídia oriundos de 2000 a 2011; e a fase três, com as GRM/jornalismo long-form de 2012 em diante. Longhi (2014) aponta para um amadurecimento da GRM e a considera um marco no jornalismo digital.

A despeito disso, quando se procura o lugar dos especiais multimídia no contexto do jornalismo digital, Longhi (2010) ressalta para uma profusão de

9 Reconhecemos as diferenças conceituais que existem em termos como jornalismo on-line e jornalismo digital - ambas utilizadas por Longhi $(2010,2014)$ em contextos distintos -, mas optamos por manter as expressōes utilizadas pela autora.

10 Essa classificação é realizada com base nos softwares e técnicas utilizados, além de características de navegação e design (Longhi, 2014). 
formatos multimídia, tais como vídeos, entrevistas em áudio, slide-shows etc., que são oferecidos mais como conteúdos justapostos do que integrados de fato. A integração ocorre efetivamente em formatos como os especiais multimídia e inclui fotorreportagens, áudio-slide-shows, gráficos interativos, dentre outros.

\section{Multimidialidade por justaposição: considerações sobre os especiais multimídia do LabCom/MPEG}

Embora demaneira ainda tímida-e em decorrência da falta de recursos humanos e financeiros -, as séries especiais multimídia produzidas pelo LabCom/MPEG e direcionadas para usuários da internet apresentam alguns aspectos da inovação que podem ser observados. Não fogem, contudo, às características próprias do discurso jornalístico digital, a exemplo da hipertextualidade (incluindo os hiperlinks e a hipermídia), a multimidialidade e a interatividade (Longhi, 2010). Por hipertexto nos referimos ao resultado da aplicação da hipertextualidade, que em termos práticos diz respeito à "capacidade de ligar textos digitais entre si” (Salaverría, 2005, p. 30).

Certamente, o que é nomeado de "especiais multimídia" pela equipe do LabCom do MPEG, um gênero jornalístico característico dos meios digitais (Longhi, 2010), não se enquadra na complexidade do escopo da definição de Longhi (2010), cuja compreensão concebe os especiais como um produto e/ ou formato que apresenta as informações dispostas em distintos tipos de linguagens, agregando gêneros diferentes do jornalismo e recombinando variadas linguagens em narrativas.

Ainda que, na própria estrutura narrativa das reportagens apresentadas, o texto desenvolva uma narrativa mais longa e não obedeça a certos princípios da pirâmide invertida ${ }^{11}$, esses aspectos não são suficientes para enquadrar os especiais multimídia no conceito proposto por Longhi (2010), embora possuam aproximações e sejam aspectos que configurem uma renovação e até inovação da narrativa jornalística no ambiente digital, segundo Flores (2010).

No entanto, em decorrência da migração do site do MPEG para uma nova plataforma, a maioria dos hiperlinks para vídeos nos canais do YouTube, gifs e download dos paper toys e papéis de parede não estavam acessíveis, na ocasião de nossa análise em janeiro de 2019, nas dez reportagens ${ }^{12}$. Trata-se de um grave problema, já que afeta o princípio de hipertextualidade do conteúdo, uma das características base do jornalismo on-line.

11 O modelo padrão da pirâmide invertida apresenta a notícia a partir das informações mais importantes (lead) para as menos relevantes (sublead e corpo do texto), segundo Flores (2017). O intuito desse distanciamento, no contexto das séries multimídia do MPEG, é poder descrever as características, estudos científicos desenvolvidos na instituição e o manejo em cativeiro no parque dos temas das reportagens (animais, aves ou plantas, portanto).

12 Nas matérias, apenas alguns links das vídeos-reportagens no YouTube e currículos de fontes na base Lattes ainda funcionavam. 
Além disso, há uma limitação preocupante no novo portal no que tange à interatividade, uma vez que não há um espaço para as seções de comentários do público nas matérias (Figura 3), nem mesmo por meio de um sistema que possibilita comentários em matérias de portais a partir de sites de redes sociais como o Facebook (comments plugin). Portanto, este tipo de participação limita-se aos sites de redes sociais usados pela instituição. Ademais, há apenas quatro botões disponíveis, no canto superior direito de cada matéria, que permitem ao usuário somente compartilhar os links das notícias via Facebook, Telegram, Linkedin e Twitter. A interatividade, desta maneira, é ainda bastante limitada e um maior grau/nível de capacidade desta é restringido (Rost, 2014) - o que pode ter sido um problema em decorrência da migração para o novo portal do museu.

Isso se soma ao fato das séries especiais não possuírem um lugar na estrutura do portal, ou seja, uma seção própria na qual poderia ocorrer a exploração dos elementos multimídia e da criatividade jornalística - o que se verificou a partir da dificuldade de localizar as reportagens. O conteúdo encontra-se, assim, dependente dentro da estrutura noticiosa do portal, uma vez que o espaço para o conteúdo diário é priorizado. A única aba existente refere-se ao projeto Viva Amazônia que, além dos links estarem inacessíveis, está desatualizada.

Antes de prosseguirmos, essa questão demanda imediatamente que se enderece uma contextualização. Grande parte desse problema, acreditamos, é decorrente do SETIC da instituição não atuar de maneira integrada ${ }^{13}$ ao SCS na manutenção do portal ${ }^{14}$. Essa situação apareceu com certa frequência na entrevista com a chefe do SCS, que demonstrou nítido descontentamento diante do trato da equipe do SETIC com as produções jornalísticas publicadas em sites específicos produzidos pelo LabCom. Um exemplo claro é o extinto site sobre a Revitalização do Parque Zoobotânico do museu, uma das primeiras iniciativas do LabCom, surgida para abrigar todo o material que havia sido veiculado sobre a revitalização.

Colocamos os cantinhos preferidos pelas pessoas, os trajetos que elas gostavam, quem gostava de fazer o quê aqui dentro do parque, colocamos em vídeos, gifs, podcasts, galerias de imagens. Enfim, a gente deixou ali para o público ter acesso [...]. Recentemente tiraram ele do ar, porque isso foi uma decisão que foi apenas comunicada pela área de Tecnologias da Informação, o SETIC, que não nos deu nenhuma justificativa para fazer isso. Enfim, pode ser que volte, pode ser que não volte. Todo esse conteúdo está perdido ou, pelo menos, não acessado [...]. (Joice Santos. Entrevista pessoal. Janeiro de 2019)

Exemplos como esse nos permitem questionar até que ponto as decisões do SCS e suas inovações possuem um respaldo ou se tornam elementos de gestão da organização em nível institucional. O que observamos é a existência de decisões

13 Ao menos, não durante a transição de conteúdos para o novo endereço eletrônico.

14 No gerenciamento compartilhado entre o SETIC e o SCS, a organização do conteúdo fica a cargo do SCS e a base de dados e outros aspectos mais internos e técnicos da plataforma ficam a cargo do SETIC. 
Figura 3 - Ausência de espaço para comentários dentro da reportagem da onça-pintada na série "Aves e Mamíferos".

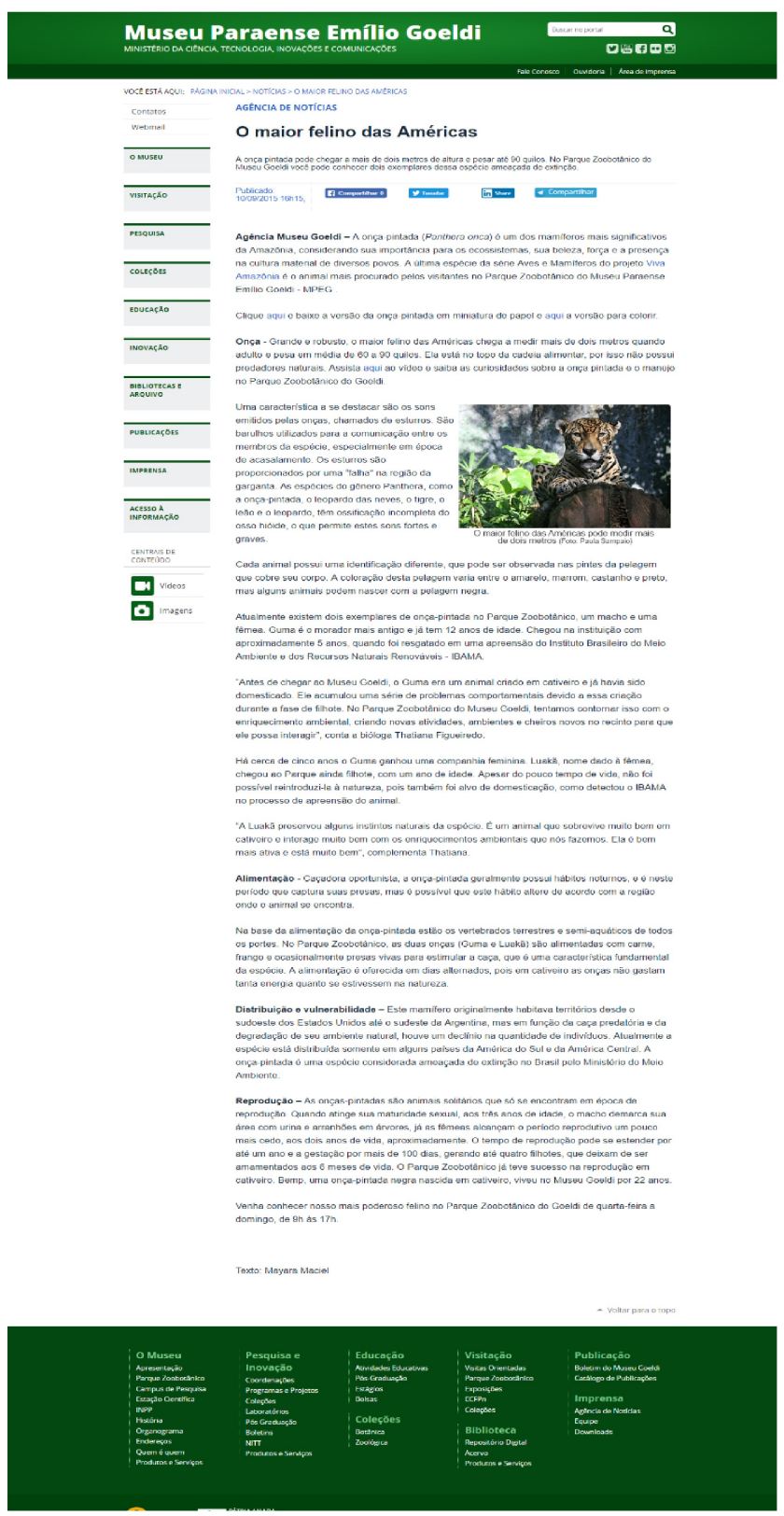

Fonte: Portal do Museu Goeldi, 2015. 
e escolhas inovadoras planejadas e desenvolvidas por um grupo e ambiente inovador (a SCS), de vanguarda dentro da organização, que enfrenta constantes resistências nos processos internos do museu.

A dependência, e aparente falte de autonomia, do SCS com relação ao SETIC do MPEG configura-se como um dos empecilhos ao objetivo de ser um "núcleo de produção e inovação em comunicação pública da ciência na Amazônia" (Santos, 2009, n.p.), bem como na experimentação de linguagens para a produção de material jornalístico e publicitário com foco para a internet, dispositivos móveis e rádio. Isso evidencia que enquanto não houver uma colaboração efetiva entre profissionais dos dois setores, haverá conflitos que poderão sustar as estratégias de difusão e popularização da ciência por parte da instituição.

Que não se pense, pois, que uma área reclusa das demais, sem interações, possa permitir o fomento à inovação. Cooperação é uma palavra de ordem, norteadora de qualquer atividade inovativa. Ações integradas e conjuntas entre áreas diversas abrangidas pela Comunicação são fundamentais para a consolidação de uma dada proposta inovadora. As atividades devem ocorrer em nível institucional e, se possível, alcançar o nível necessário à cooperação na esfera interinstitucional. O SCS, bem com o LabCom, atua em colaboração com variadas áreas dentro do Museu Goeldi e com instituições parceiras, o que tem sido uma oportunidade singular para organizar a sua comunicação da ciência, mas, ao que aparenta este problema com o SETIC, abre-se margem para acreditarmos que algumas ações ocorrem de maneira insular.

Retornando à linha de raciocínio acerca da análise do conjunto das séries do LabCom, o conteúdo apresentado como "multimídia", de fato, entrega apenas imagens, textos e sons que podem ser consumidos contínua ou separadamente. Não há o uso de áudio-slide-shows, slide-shows, gráficos ou infográficos interativos no projeto. Os textos, imagens, gifs, ilustrações (papéis de parede), brindes e vídeo-reportagens, em ambas as séries, não compõem um discurso integrado, ao contrário, aparecem justapostos, isto é, como arquivos de imagens colocados de maneira desagregada e lado a lado, para usarmos a definição de Salaverría (2005).

Tampouco todos esses elementos presentes nos especiais do MPEG estão combinados em uma interface única e simples ${ }^{15}$, compondo uma unidade comunicativa na qual os elementos dialogariam entre si nas mesmas coordenadas da tela, sem haver necessidade de janelas separadas para reproduzir conteúdos específicos, como vídeos, galerias de fotos, mapas, ilustrações e fotografias, por exemplo. Ao invés disso, para acessar os vídeos, as matérias possuem links que redirecionam o público para a página do MPEG no YouTube, e o mesmo se repete com as miniaturas, as quais precisam ser baixadas em um link que redireciona para o Google Drive, embora apenas os vídeos funcionem no portal atual.

15 Provavelmente, em decorrência das próprias limitações diante do portal e pela atuação 'independente' do SETIC, limitando as possibilidades operacionais e experimentais do SCS. 
Não há integração entre formatos e conteúdos, ou mesmo entre gêneros jornalísticos diversos em uma única interface, com a finalidade de criar uma unidade comunicativa e um discurso coerente, no caso dos elementos presentes nos autointitulados especiais multimídia. Dessa forma, os conteúdos, efetivamente, não oferecem uma combinação e rearranjo das respectivas linguagens, estando agrupados lado a lado, o que, para Salaverría (2005), classifica-se como multimidialidade por justaposição (Figura 4).

Assim sendo, os especiais do MPEG não se traduzem na efetiva integração e combinação dos elementos multimídia, ou seja, "um formato novo, diferente daqueles que operam para lhe dar configuração, através da combinação e rearranjo" (Longhi, 2010, p. 152). Em linhas gerais, pode-se argumentar que o uso da multimidialidade nas séries multimídia "Aves e Mamíferos" e "As Anciãs do Museu Goeldi" pode ser considerado ainda bastante modesto. Nelas, o que se apresenta como "especial multimídia", na realidade, oferece apenas imagens, textos e vídeos que podem ser consumidos separadamente ou continuamente.

Apesar disso, as vídeo-reportagens apresentam mais informações e aprofundam aspectos não tocados no texto, não repetindo o conteúdo já introduzido nas matérias - o que se trata, por sua vez, de uma das características do especial multimídia. Embora as ilustrações (papéis de parede) e as miniaturas de papel sejam interessantes, não acrescentam no conteúdo inicial: tratam-se de adereços estratégicos que buscam aproximar o público e fidelizá-lo a partir de uma abordagem que recorre ao lúdico, ao design e à arte.

A despeito de suas limitações, os usos da multimídia e de cibermeios para os conteúdos produzidos pelo LabCom, principalmente a partir do projeto Viva Amazônia, atuam "para a consolidação e/ou formação de novas memórias, de novos imaginários, sobre essa instituição que preserva parte significativa da memória da diversidade amazônica", como reforça Phillippe Fernandes (2017, p. 6). Apesar da oferta de brindes em conteúdos jornalísticos especiais não ser uma ação em si inovadora, proporciona elementos de inovação que trazem mudanças ao serem concebidos como estratégia de divulgação e de visibilidade do conhecimento científico no contexto da dinâmica de circulação e consumo dos especiais multimídia do LabCom na internet. Não se trata, pois, de uma invenção, de uma ideia ou produto novo por completo. Essa perspectiva, antes, segue e reforça uma concepção de inovação como introdução de diferenciais ou melhorias em formatos, produtos, tecnologias e processos, reconfigurando-as de forma inovadora (Martins, 2018).

Ademais, os papéis de parede, ilustrados a partir da técnica aquarela, reforçam aspectos da regionalidade, do imaginário e da história amazônica atrelada às espécies de plantas e árvores retratadas na série multimídia. $\mathrm{Na}$ comunicação e nojornalismo, as inovações, portanto, manifestam-se de variadas maneiras, desde produtos novos, interações individuais e grupais emergentes, no tratamento de questões em ambientes diversos, no desenvolvimento do negócio e na construção de novos processos (Giacomini Filho, 2015). 
Figura 4 - Exemplo de multimidialidade por justaposição na reportagem especial sobre a Araracanga, na série "Aves e Mamíferos".
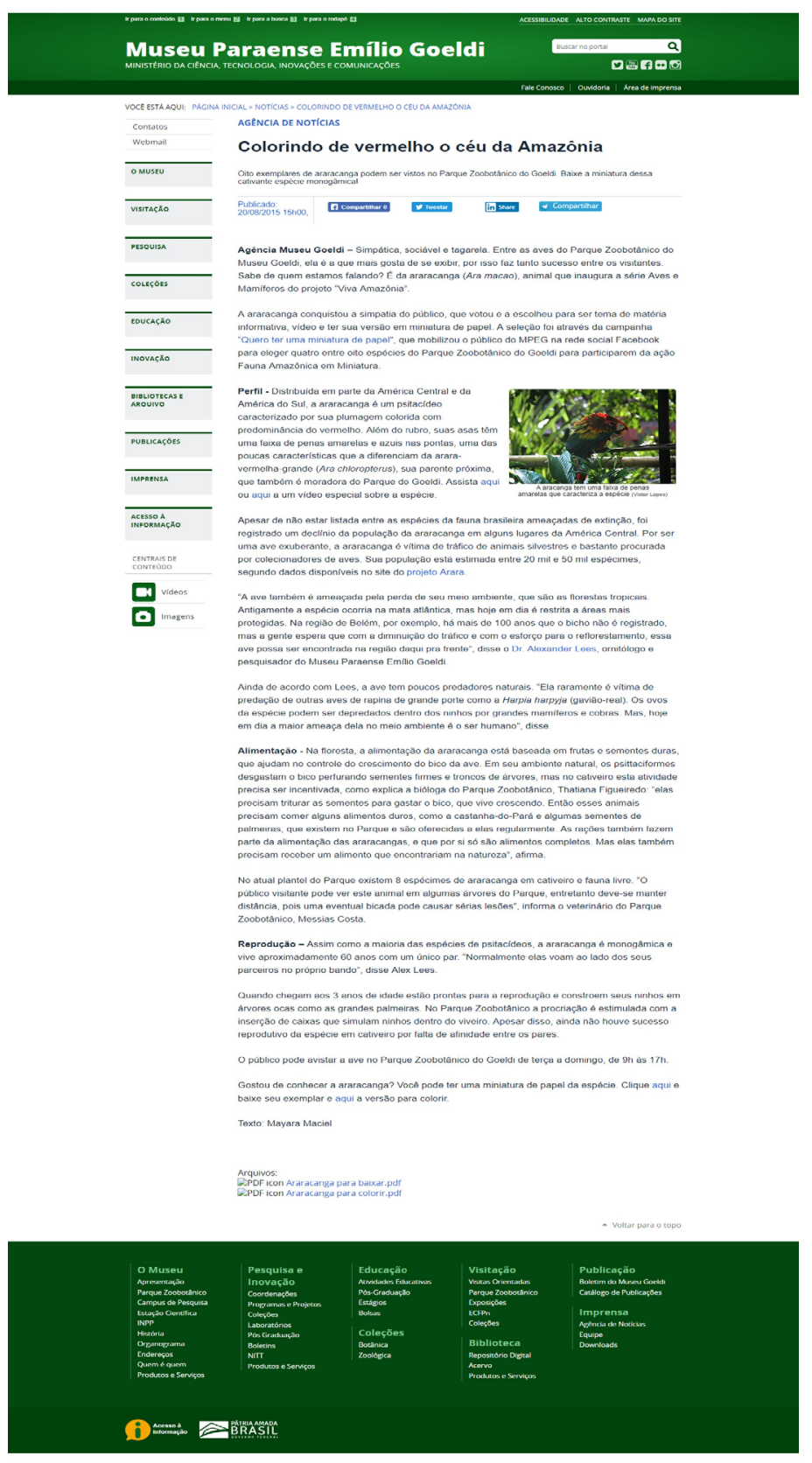

Fonte: Portal do Museu Goeldi, 2015. 
Portanto, o conjunto dessas ações constitui significativas alterações nas dinâmicas de produção e circulação de conteúdos produzidos para as séries multimídia, também integrando uma forma de inovação incremental no jornalismo (Giacomini Filho, 2015). Dito de outra forma, embora essas ações, produtos e processos do LabCom não se enquadrem na perspectiva de inovação radical de Gino Giacomini Filho (2015), isto é, que significa ruptura de paradigmas, o conjunto dessas práticas pode ser percebido como pequenos avanços de ordem organizacional e produtiva - o que nos permite tipificá-lo em inovações incrementais. Como reforça o autor,

a criação de um anúncio, o lançamento de uma editoria jornalística, a elaboração original de uma peça de campanha publicitária, um novo ângulo de abordagem de uma matéria na imprensa representam inovações, uma vez que desenvolvem processos e até novos produtos na estrutura organizacional. (Giacomini Filho, 2015, p. 78-79)

Portanto, a maioria dos aspectos de inovação identificados no jornalismo científico desenvolvido no LabCom do MPEG demarcam um tipo de inovação incremental ou relativa, isto é, "quando algo que já existe é feito de forma diferenciada ou diversificada" (Martins, 2018, p. 44) - ou "especialmente no sentido de que há agora uma nova concatenação de ações já praticadas, rearranjadas de forma inovativa" (Flores, 2017, p. 179).

Seguindo essa abordagem, ainda que as séries multimídia analisadas não representem uma inovação substancial (Rossetti, 2013) no jornalismo de modo geral, na medida em que não constituem algo inédito por completo e seguem um padrão majoritariamente justaposto - seja na disposição de itens presentes na página no portal, no uso de hiperlinks, seja na relação estabelecida entre diferentes linguagens, como vídeos, imagens e textos -, possuem configurações que indicam aspectos de uma inovação qualitativa, ligada à criatividade, que "produz a novidade" (Rosseti, 2013, p. 69).

Por fim, no contexto do jornalismo científico e da comunicação da ciência em instituições de pesquisa, ensino e extensão, as séries multimídia analisadas constituem-se como uma inovação. Ao tratar sobre o modo como a divulgação científica é realizada pelas instituições, Joice Santos destaca uma forma padrão na produção jornalística das instituições científicas: "o que as pessoas faziam normalmente, ou que fazem ainda nas instituições? Ou elas fazem um vídeo, ou fazem isso ou fazem aquilo. E a gente juntou, juntou as coisas, convergiu os formatos" (Joice Santos. Entrevista pessoal. Janeiro de 2019).

A ciência, neste sentido, pode encontrar no cenário da convergência midiática e da inovação jornalística uma alternativa de experimentação de processos que auxiliem na melhor divulgação do conhecimento científico, a fim de dar visibilidade para suas ações, democratizar o saber, aproximar os mais distintos públicos e valorizar a participação e cidadania na Amazônia. 


\section{Considerações finais}

A temática científica exige frequente necessidade por abordagens e tratamentos diferenciados e cuidadosos para com o conteúdo a ser veiculado, no intuito de tornar o consumo da informação o mais interessante possível. Como defende Beltrão (2010a), é uma tarefa complexa pensar em estratégias que busquem despertar o sentimento de curiosidade para temas relacionados à ciência, já que esta padece perante dois obstáculos: a falta de disponibilidade dos produtores de conhecimento em pôr em evidência suas novas descobertas; e de interesse da mídia em publicizá-las. Acreditamos, assim, que a inovação jornalística seja uma oportunidade para utilizar linguagens e formatos que ofereçam mais apelo diante dos múltiplos públicos existentes e das dificuldades para retê-los em temas da ciência, dada a dinamicidade e a variedade de ofertas de conteúdos com a crescente diversificação de canais e de mídias provocada nas últimas décadas, sobretudo a partir dos avanços tecnológicos.

$\mathrm{Na}$ era das plataformas digitais, o jornalismo é impulsionado a transformar as experiências de ler, ver e ouvir e precisa ser mais atraente para subsistir. Nesse sentido, as instituições e organizações precisam estar abertas para experimentações e mudanças na forma como se comunicam com o público, percebendo não somente os aspectos tecnológicos das inovações, mas também os culturais (Martins, 2018). Como ressalta Flores, "a chave para um jornalismo mais bem aceito ou mais próximo de um público também inovador, parece se concentrar cada vez mais na antecipação cultural e comportamental de seus consumidores" (2017, p. 181).

O conjunto das propostas do jornalismo aponta que a atividade está sendo continuamente repensada em função das variadas instâncias, seja nos processos, formatos, distribuição ou modelo de negócio/gestão (Flores, 2017). Trata-se de um ambiente que tem impelido o jornalismo, sobretudo o científico, a investir em estratégias de inovação, em meio a um mercado de altos níveis competitivos (Martins, 2018; Martins et al., 2018). É um modelo que impõe desafios à existência dos serviços de comunicação em instituições de pesquisa que se veem, hoje, provocadas a inovar tanto nos modelos de financiamento quanto nas formas de gestão, produção, narrativas, conteúdos, formatos e tecnologias. Isso denota, portanto, que os modelos de negócio e/ou gestão impactam tanto as grandes corporações de mídia como os serviços de comunicação dessas instituições.

Neste sentido, o investimento em estratégias de inovação no jornalismo desponta como uma alternativa para as instituições se adequarem às mudanças impostas pelos tempos atuais. Observamos que o LabCom do MPEG, a partir das suas séries especiais multimídia, promove inovações incrementais (Giacomini Filho, 2015) ou relativas (Martins, 2018) em seus conteúdos e narrativas, possuindo configurações que indicam aspectos de uma inovação qualitativa, ou seja, cujas inovações são ligadas à criatividade (Rossetti, 2013). 
A iniciativa do LabCom do MPEG demonstra que a inovação pode ser um caminho a ser percorrido perante a mudança de hábito dos públicos e da necessidade de tornar o conteúdo interessante. A experiência de ler, ver e ouvir no jornalismo científico produzido pelo Museu Paraense Emílio Goeldi precisa ser tão atraente como o próprio conjunto de coleções vivas que compõem os acervos científicos do seu Parque Zoobotânico, o qual recebe cerca de 4,00 mil visitantes por ano. Para isso, seguindo a perspectiva defendida em trabalho anterior (Martins, 2018), é preciso que o museu esteja disposto e aberto às mudanças e experimentações e explorar, sobretudo, a dimensão cultural da inovação diante do desafio de visibilizar o conhecimento cientifico, envolver os mais diferentes públicos e democratizar os saberes na Amazônia.

\section{Referências bibliográficas}

Beltrão, J. (2010a). Comunicação de Ciência: prática e necessidade de pesquisa. In: J. Beltrão (Org.), Pesquisa em comunicação de ciência na Amazônia Oriental Brasileira: a experiência recente no Museu Paraense Emílio Goeldi (pp. 9-15). Belém: MPEG.

Beltrão, J. (2010b). Pesquisa em Comunicação de Ciência na Amazônia Oriental Brasileira: a experiência recente no Museu Paraense Emílio Goeldi. In: J. Beltrão (Org.), Pesquisa em comunicação de ciência na Amazônia Oriental Brasileira: a experiência recente no Museu Paraense Emílio Goeldi (pp. 19-31). Belém: MPEG.

Boni, V. \& Quaresma, S. (2005). Aprendendo a entrevistar: como fazer entrevistas em ciências sociais. Revista Eletrônica dos Pós-Graduandos em Sociologia Política da UFSC, Santa Catarina, 2(1), 68-80.

Caldas, G. (2011). Mídia e políticas públicas para a comunicação da ciência. In: C. Porto, A. Brotas \& S. Bortoliero. (Org.), Diálogos entre ciência e divulgação científica: leituras contemporâneas (pp-19-36). Salvador: EDUFBA.

Fernandes, P. (2017). Bordando memórias e despertando imaginários na era da convergência: o projeto Viva Amazônia do LabCom do Museu Paraense Emílio Goeldi. Relatório do Projeto de Capacitação Institucional (pp. 1-15). Belém: MPEG.

Flores, A. (2017). Jornalismo de inovação: um conceito múltiplo. Brazilian Journalism Research, 13(2), 156-179. DOI: https://doi.org/10.25200/BJR.v13n2.2017.970

Giacomini Filho, G. (2015). A responsabilidade social como fator de inovação para a comunicação. Comunicação \& Inovação, 16(31), 77-93 DOI: http://dx.doi.org/10.13037/ ci.vol16n31.3260

Longhi, R. (2010). O nome das coisas: em busca do especial multimídia. Estudos em Comunicação, 2(7), 149-161. Disponível em: http://ec.ubi.pt/ec/o7/vol2/longhi.pdf

Longhi, R. (2014). O turning point da grande reportagem multimídia. Revista FAMECOS, 21(3), 897-917. DOI: http://dx.doi.org/10.154.4.8/1980-3729.2014.3.18660

Longhi, R. \& Flores, A. (2017). Narrativas webjornalísticas como elemento de inovação: casos de Al Jazeera, Folha de S. Paulo, The Guardian, The New York Times e The Washington Post. Intercom, 40(1), 21-40. DOI: http://dx.doi.org/10.1590/1809-584,4201712

Martins, E. (2018). Modos e sentidos da inovação no jornalismo. Comunicação \& Inovação 19(39), p. 35-49. DOI: https://doi.org/10.13037/ci.vol19n39.4955 
MACEDO \& MARTINS

Martins, E., Castro, M. \& Vinagre, I. (2018). Transmídia e redes sociais: aspectos da inovação no telejornalismo. Revista Observatório, 4(3), p. 571-60o. DOI: https://doi.org/10.20873/ uft.2447-4266.2018v4n3p571

Rost, A. (2014). Interatividade: Definições, estudos e tendências. In: J. Canavilhas (Org.), Webornalismo: 7 características que marcam a diferença (pp. 53-88). Covilhã: UBI.

Rossetti, R. (2013). Categorias de inovação para os estudos em comunicação. Comunicação EInovação, 14(27), 63-72. DOI: http://dx.doi.org/10.13037/ci.vol14n27.2262

Salaverría, R. (2005). Redacción Periodística en Internet. Pamplona: EUNSA.

Salaverría, R. (2014). Multimedialidade: Informar para cinco sentidos. In: J. Canavilhas (Org.), Webornalismo: 7 características que marcam a diferença (pp. 25-51). Covilhã: UBI.

Sampieri, R., Collado, C. \& Lucio, P. (2014). Metodología de la investigación. 6a ed. Cidade do México: McGraw-Hill.

Santos, J. (2009). Laboratório de Comunicação Pública da Ciência na Amazônia (Pará). In: J. Santos. Projetos de desenvolvimento - Currículo Lattes. Disponível em: http://lattes. cnpq.br/9748387321631271

Yin, R. (2001). Estudo de caso: planejamento e métodos. Tradução: Daniel Grassi. 2a ed. Porto Alegre: Brookman. 